Research Article

\title{
Practices and Attitudes of Dental Loupes and Their Relationship to Musculoskeletal Disorders among Dental Practitioners
}

\author{
Khalid Aboalshamat $\mathbb{D},{ }^{1,2}$ Ola Daoud, ${ }^{3}$ Lina Ayman Mahmoud, ${ }^{3}$ Sakina Attal, ${ }^{3}$ \\ Rahaf Alshehri, ${ }^{3}$ Duaa Bin Othman, ${ }^{3}$ and Reem Alzahrani ${ }^{3}$ \\ ${ }^{1}$ Dental Public Health Division, Preventative Dentistry Department, College of Dentistry, Umm Al-Qura University, Makkah, \\ Saudi Arabia \\ ${ }^{2}$ Medicine and Medical Science Research Center, Deanship of Scientific Research, Umm Al-Qura University, \\ Makkah, Saudi Arabia \\ ${ }^{3}$ Alfarabi College, Jeddah, Saudi Arabia
}

Correspondence should be addressed to Khalid Aboalshamat; dr.khalid.sh@hotmail.com

Received 22 April 2020; Revised 8 July 2020; Accepted 18 July 2020; Published 30 July 2020

Academic Editor: Carlos A. Munoz-Viveros

Copyright $\odot 2020$ Khalid Aboalshamat et al. This is an open access article distributed under the Creative Commons Attribution License, which permits unrestricted use, distribution, and reproduction in any medium, provided the original work is properly cited.

\begin{abstract}
Objective. A dental loupe is a tool used by many dentists and dental students to improve visual field and performance. This study aims to assess the practices and attitudes about dental magnification loupes and their relationship to musculoskeletal disorders. Materials and Methods. A cross-sectional study was conducted involving 400 dental students and dentists in four dental colleges in Jeddah, Saudi Arabia. The mean age was 28.35 years $(S D=8.50)$, and $56 \%$ of the participants were male. Also, $70.75 \%$ were students or interns, while $29.25 \%$ were dentists. Data gathering was conducted using a questionnaire that was composed of four sections: demographic, magnification devices usage, attitude toward dental loupes, and the Nordic questionnaire to assess musculoskeletal disorders. Results. A total of $66 \%$ of participants had used dental magnification tools before, but only $12.25 \%$ were using dental loupes at the time of the study. The main reported advantages of dental loupes were comfort in vision (59.25\%) and improved work accuracy (53\%), while the main disadvantage was difficulty in visual measurement (28.5\%). A total of $73.25 \%$ reported that price was the main barrier to the use of dental loupes. Lower back (63.5\%), neck (65.25\%), and shoulder (46.25\%) pain were the most frequently reported areas of discomfort. There was a significant relationship $(<0.05)$ between the use of dental loupes and lowered levels of reported discomfort in the lower back, neck, shoulders, elbows, upper back, and feet. Conclusion. There are few dental professionals who use dental loupes in Saudi Arabia. There was a significant relationship between dental loupes use and reduction of musculoskeletal disorders among dental students and dentists.
\end{abstract}

\section{Introduction}

Dental magnification loupes are a tool used by dentists and dental hygienists to enhance their ability to visualize what cannot be seen by the naked eye [1]. Loupes, preceded by the dental operating microscope, were invented in the 1980s to increase success rates for surgical endodontic treatment [2]. Loupes are usually attached to glasses frames using different mounting formats, including fully adjustable front lens loupe, limited adjustable lens loupe, and through-the-lens loupes [3,4]. Each one of these types has different abilities in terms of adjustment and ease of use. In addition, loupes are available with different magnification strengths [5].

Several studies have reported that the use of loupes among dental students [6-8], dentists $[9,10]$, and even dental hygienists $[11,12]$ has become popular in many countries around the world. Magnification in dentistry was promoted to be used for oral surgical flaps, dental tissue grafts, surgical periodontal treatments [13], various steps to endodontic treatment $[14,15]$, caries detection, and cavity 
preparation [16]. Studies found many advantages to using loupes, such as decreased work time, increased work quality $[7,8]$, and easier detection of unfound canals [14].

More importantly, a systematic review pointed out that using loupes was found to be beneficial for reducing musculoskeletal disorders (MSDs) that are common among dental professionals, especially those in the hands, arms, and shoulders [17]. The study found little evidence, however, that loupes were effective for easing neck pain. Other articles indicated the importance of using loupes for dental professionals over 40 years old who have accentuated MSD problems due to visual deficiencies from increasing age [18]. This is important as the prevalence of MSDs is high among students, as has been reported in Saudi literature (43\% to $95.8 \%$ ) [19], and also among dentists, as indicated by another systematic review (64\% to 93\%) [20], and studies in Saudi Arabia (85\% to 90.2\%) [21, 22]. A study in Saudi Arabia found that the majority $(70 \%)$ of dental students are ignorant about dental ergonomics, and half of them were aware of MSD. Also, most of them were unaware of MSDs prevention of treatment modalities [23]. In fact, MSDs are found to be a major contributor to early retirement and poor quality of life [20], which justifies the importance of loupes as an aid to alleviate this problem.

However, many articles pointed out that the advantages with loupes can best be fulfilled when proper knowledge and skills are acquired for their use $[8,24]$, especially during the early years of undergraduate dental study $[6,10,25]$. However, few studies have assessed levels of knowledge, attitudes, and practices using loupes and magnification devices among dentists and dental students. Studies have reported that $21.9 \%$ and $28 \%$ of dental students use loupes in, respectively, Saudi Arabia [6] and the UK [9], which are lower than the reported percentages of dentists using loupes in the UK (44\%) [9], or the United States (56\%) [10]. In fact, the most commonly used magnification tool among students was dental loupes, followed by magnification lenses [6]. Also, around $91.6 \%$ of students advocated for its effectiveness at improving work quality $[6,9]$. The favored loupes were 2.5 times magnification and through-the-lens types [9]. Price was the most common barrier to the use of loupes according to some studies, in addition to a lack of experience $[9,25]$. It should be noted that there is a proportion of dental faculty members who believe that loupes are not very important for undergraduate students [10], while some dental students believe that using loupes has disadvantages in that dentists might rely on loupes in their future dental practice [6].

There are very few studies that have assessed the use of dental loupes in Saudi Arabia and the relationship of loupe use to MSDs. Thus, this study aimed to assess usage of and attitudes about dental magnification loupes and the relationship of loupe use to MSDs among dental students and dentists in Jeddah, Saudi Arabia.

\section{Materials and Methods}

Participants were recruited using convenient sampling in this cross-sectional study. Study inclusion criteria were either faculty members, interns, or students at clinical levels (fourth, fifth, and sixth years) who were currently studying or on the job in dental colleges. Participants who did not sign the study consent were excluded. Data were collected from November to December 2019 from four dental colleges: Alfarabi Medical College (FMC), Ibn Sina National College (ISNC), Batterjee Medical College (BMC), and King Abdulaziz University (KAAU). The minimum required sample size was calculated using an expected prevalence of $50 \%$, a confidence interval of $95 \%$, and an alpha level of $5 \%$, which resulted in 385 participants. To overcome an expected nonresponse rate of $30 \%, 500$ participants were invited to answer the study's hard copy self-reported questionnaire. Participants answered the study questionnaire during breaks and free time, and all participants signed the study consent form before completing the questionnaire. All answers were taken anonymously, although the research team contacted study participants face to face. The time to answer the questionnaire was three to five minutes.

The questionnaire was composed of four sections as shown in Table 1. The questions in sections two and three were derived from previous studies, with modifications $[6,9,25]$. Section four included the Nordic work-related MSD assessment [26], which is a well-validated questionnaire [27-30] that has been used for decades. In addition, the questionnaire as a whole was tested in a pilot test with 10 participants not included in the main study assessing validation, especially for sections two and three in terms of content, organization, language, syntax, and logical flow.

Data analysis was conducted using SPSS v.21 (IBM Corp., Armonk, NY, USA). Data were analyzed using multiple logistic regression and chi-square tests and were presented as descriptive statistics by the mean, standard deviation, frequency, and percentages. A $P$ value of less than 0.05 was considered significant. The study was approved by the Institutional Review Board of Umm Al-Qura University, Faculty of Dentistry, with number 154-19.

\section{Results}

A total of 400 dental students and dentists participated in this study, for a response rate of $80 \%$, with a mean age of 28.35 years and standard deviation (SD) of 8.50. Participants' mean years in practice was $3.26(\mathrm{SD}=7.29)$. Of the participants, $283(70.75 \%)$ were students or interns, while 117 (29.25\%) were dentists. Participant demographic data are shown in Table 2.

A total of $268(67 \%)$ respondents had used magnification tools in dentistry in the past. Some of them used different devices simultaneously while others used only one at a time, and $240(60 \%)$ used dental loupes, 15 (3.75\%) used a magnifying glass, and $31(7.75 \%)$ used a dental microscope. Among the current users of these tools, only 49 participants (12.25\%) used dental loupes in their clinical practice. The multiple logistic regression (backward elimination technique) showed that none of the demographic variables had a significant relationship with current use of dental loupes. In other words, age, years of education, gender, educational level, and college type were not significantly related to the use of dental loupes. 
TABLE 1: The study questionnaire.

\begin{tabular}{|c|c|}
\hline Section & Question details \\
\hline One & $\begin{array}{l}\text { Questions about demographic data, including gender, age, academic year/work status, years of practice, financial status, and place } \\
\text { of study/work. }\end{array}$ \\
\hline Two & $\begin{array}{l}\text { Questions asking about the participant's use of magnification devices (dental loupes, magnification glasses, and dental } \\
\text { microscopes) and the sources of their knowledge about dental loupes. }\end{array}$ \\
\hline Three & $\begin{array}{c}\text { Attitude questions, including questions regarding which dental specialty should use dental loupes, the advantages and } \\
\text { disadvantages of using loupes, and barriers to using dental loupes. }\end{array}$ \\
\hline Four & $\begin{array}{c}\text { The Nordic work-related MSD assessment [26], using selected items that investigated upper back, lower back, hip/thigh, neck, } \\
\text { shoulder, elbow, wrist/hand, knee, and ankle/foot pain. }\end{array}$ \\
\hline
\end{tabular}

Table 2: Participant demographic data.

\begin{tabular}{lcc}
\hline Variable & $N$ & $\%$ \\
\hline Gender & & \\
Male & 224 & 56.00 \\
Female & 176 & 44.00 \\
Education/position & & \\
2nd year & 2 & 0.50 \\
3rd year & 5 & 1.30 \\
4th year & 7 & 1.80 \\
5th year & 40 & 10.00 \\
6th year & 79 & 19.80 \\
Intern & 150 & 37.50 \\
General dentist & 40 & 10.00 \\
Postgraduate & 6 & 1.50 \\
Specialist & 53 & 13.30 \\
Consultant & 18 & 4.50 \\
College & & \\
Private & 277 & 30.75 \\
Governmental & 123 & \\
\hline
\end{tabular}

Participants had received information about dental loupes from different resources, and sometimes from multiple resources, which is explained in Figure 1. Participants reported different advantages and disadvantages to using dental loupes, and some participants reported more advantages than disadvantages. This is illustrated in Table 3. Participants also reported different barriers to using dental loupes when participants were able to report more than one barrier, as shown in Table 4.

Participants varied in their opinions regarding the use of dental loupes in different dental specialties, with some participants believing loupes can be used in more than specialty, as shown in Figure 2.

Participants reported different levels of musculoskeletal pain in various parts of their body and pain experienced during the prior seven days, as shown in Table 5. Also, using chi-square test and Fisher's exact test, current users of dental loupes were found to have significantly less trouble in their lower back, neck, shoulders, elbows, upper back, and feet, as shown in Table 6.

\section{Discussion}

This study aimed to assess the use of and attitudes toward dental magnification loupes and their relationship to MSDs among dental students and dentists. Two-thirds of the participants had used dental magnification tools before, and around one in every 10 was currently using dental loupes in a dental practice. The majority believed that dental loupes improve visual abilities and dental performance, while some others claimed that dental loupes cause visual measurement problems or pain in the neck and shoulders. Price was the main barrier to the use of dental loupes. While dental loupes have been associated with lowered levels of MSDs in most parts of the body, around half of the participants had MSDs in the neck, shoulder, or lower back.

Despite the fact that $60 \%$ of the participants in this study had used dental loupes before, the percentage of current users was low at $12.3 \%$. In fact, this proportion is less than has been found in similar studies in the United Kingdom (27.7\% to $44 \%$ among faculty members and students) [9] and the United States (53.7\% among faculty members) [10]. This also was lower than a similar local study in Saudi Arabia (21.9\% among students and residents) [6]. This might be because previous studies $[6,10,31]$ assessed current users of various types of magnification all together and did not restrict the assessment to only dental loupes, such as was done in this study. Furthermore, the previous study in Saudi Arabia was conducted in 2017, and since that time, there has been an increase in taxes for some items in Saudi Arabia accompanied by a reform phase of Vision 2030 [32], so buying dental loupes might be seen as more a luxury than a necessity because it is not mandatory to use them in dental faculties in Saudi Arabia [6]. This seems to be supported by $73.25 \%$ of participants stating that the cost of dental loupes was the main barrier to their use, which will be discussed in later sections.

Most of the participants agreed that using dental loupes was most important in endodontic and surgical treatment, which is similar to previous studies $[6,25]$. Around half of the participants in this study believed that dental loupes are helpful for vision comfort, improve work accuracy, and enhance the quality of treatment, which was similar to findings from other studies $[7,8]$. Also, around one-third believed that dental loupes have no disadvantages, while among those who reported disadvantages, the most frequently cited disadvantage was difficulty in visual measuring. Also, both this study and the previous Saudi study [6] highlighted that a proportion of respondents did not want to become reliant on dental loupes in their work and considered that to be a disadvantage. This can perhaps be a result of improper use, as previous studies have found that the advantages of using dental loupes can only be tangible after proper training $[8,24]$. 


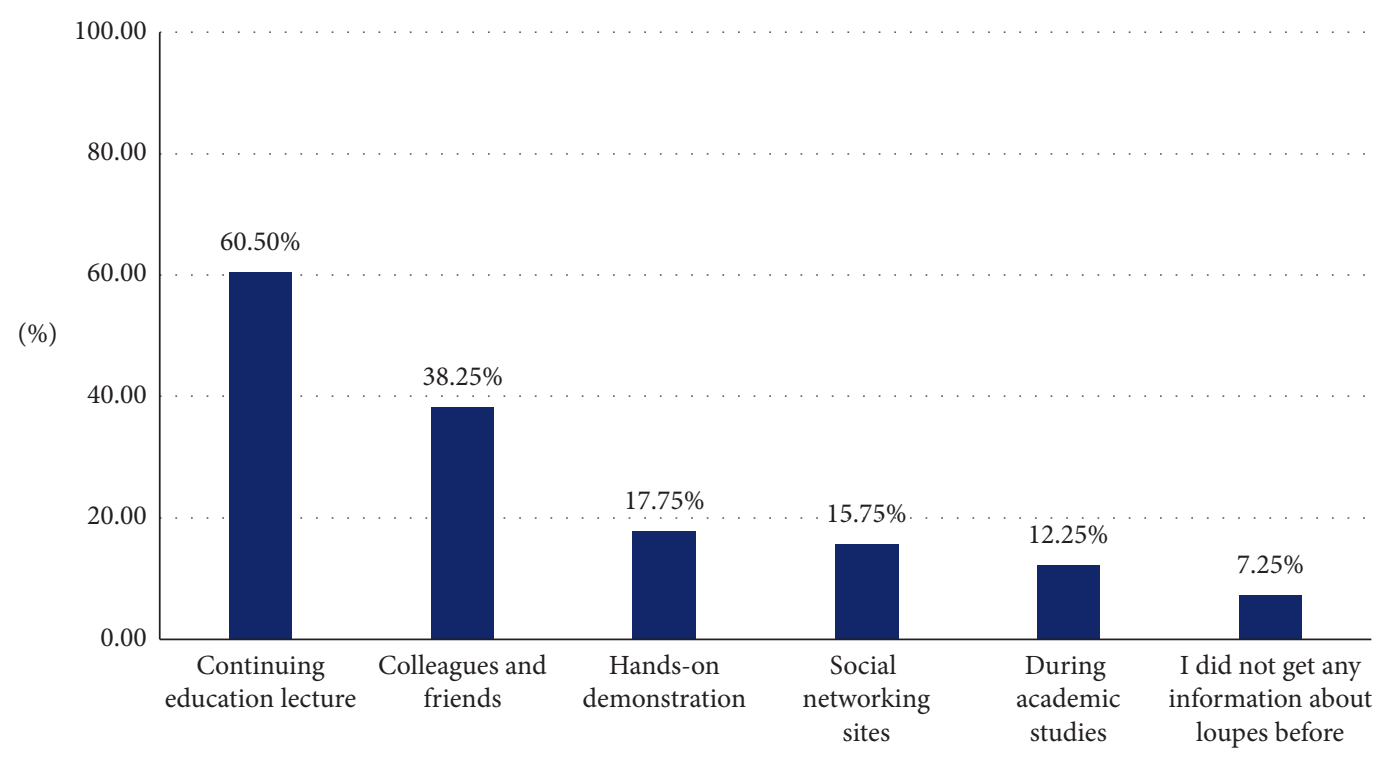

FIGURE 1: Participants' sources of information about dental loupes.

TABle 3: Advantages and disadvantages of using dental loupes.

\begin{tabular}{lcc}
\hline & $N$ & $\%$ \\
\hline Advantages & & \\
Comfort in vision & 237 & 59.25 \\
Improvement in work accuracy & 212 & 53.00 \\
Improvement in quality of treatment & 139 & 34.75 \\
Time saving & 104 & 26.00 \\
Reduces muscle pain & 88 & 22.00 \\
None of the above & 17 & 4.25 \\
\hline Disadvantages & & \\
Dental loupes have no disadvantages & 129 & 32.25 \\
Difficulties in visual measurement & 114 & 28.50 \\
Pain in neck and shoulders & 91 & 22.75 \\
Low back pain & 49 & 12.25 \\
Becoming reliant on it & 49 & 12.25 \\
Pain in hands and wrists & 41 & 10.25 \\
Have not gotten around to using it & 31 & 7.75 \\
\hline
\end{tabular}

TABle 4: Barriers to the use of dental loupes.

\begin{tabular}{lcc}
\hline Barrier & $N$ & $\%$ \\
\hline Expensive & 293 & 73.25 \\
Better without magnification & 39 & 9.75 \\
Do not want to rely on dental loupes & 32 & 8.00 \\
Loupes make no difference in work & 19 & 4.75 \\
Used to use dental loupes but stopped due to health & 7 & 1.75 \\
problems & & \\
\hline
\end{tabular}

Expense was the main barrier reported by threefourths of the participants not using dental loupes, which is supported by previous studies in the UK and India $[9,25]$. This might raise another recommendation of subsidizing the purchase of dental loupes for dental students, which could perhaps be accomplished by buying loupes in bulk for dental faculties in Saudi Arabia. Another method is to make dental loupes available during dental training so that dental students can acknowledge their importance in reducing the MSDs that have been found to be one of the primary causes of early retirement from dentistry [20].

In this study, the relationship between dental loupe use and MSDs was assessed in two ways, according to participants' attitudes and perceptions and by using statistical tests. First, for perceptions, one-fourth of the participants believed that dental loupes reduce MSDs symptoms, while $10.25 \%$ to $22.75 \%$ believed dental loupes increase MSDs. This controversial belief among participants cannot be explained, as the statistical assessment, as will be explained below, shows that using dental loupes is associated with a lowered incidence of MSDs. This finding might indicate that some dental students and dentists have misconceptions about dental loupes.

Statistically, the use of dental loupes is tied to a significantly lower prevalence of pain in the lower back, neck, shoulders, elbows, upper back, and feet. This is supported by a systematic review [17] that found dental loupes to be effective in reducing pain in the arms, hands, and neck. In fact, another Saudi study found that using dental loupes was the only ergonomic practice that was associated with a reduction in MSDs [33]. However, a recent study in the United States on the effect of mandatory dental loupe use for dental hygienists showed that the occurrence of MSDs remained the same [34]. This difference might be because the nature of the work conducted by dentists and dental hygienists is different. Regardless, our results are aligned with previous studies in indicating the importance of dental loupes as a valuable way to reduce the incidence of MSDs.

The data from this study show that the greatest percentage of sources of information about dental loupes among participants was from continuing education lectures, while a low proportion came from academic studies in universities. This is similar to the previous local study [6], which highlighted that dental loupes had not been formally taught in academic lectures. However, this finding is contradictory to a study in India, where $59.5 \%$ had received their 


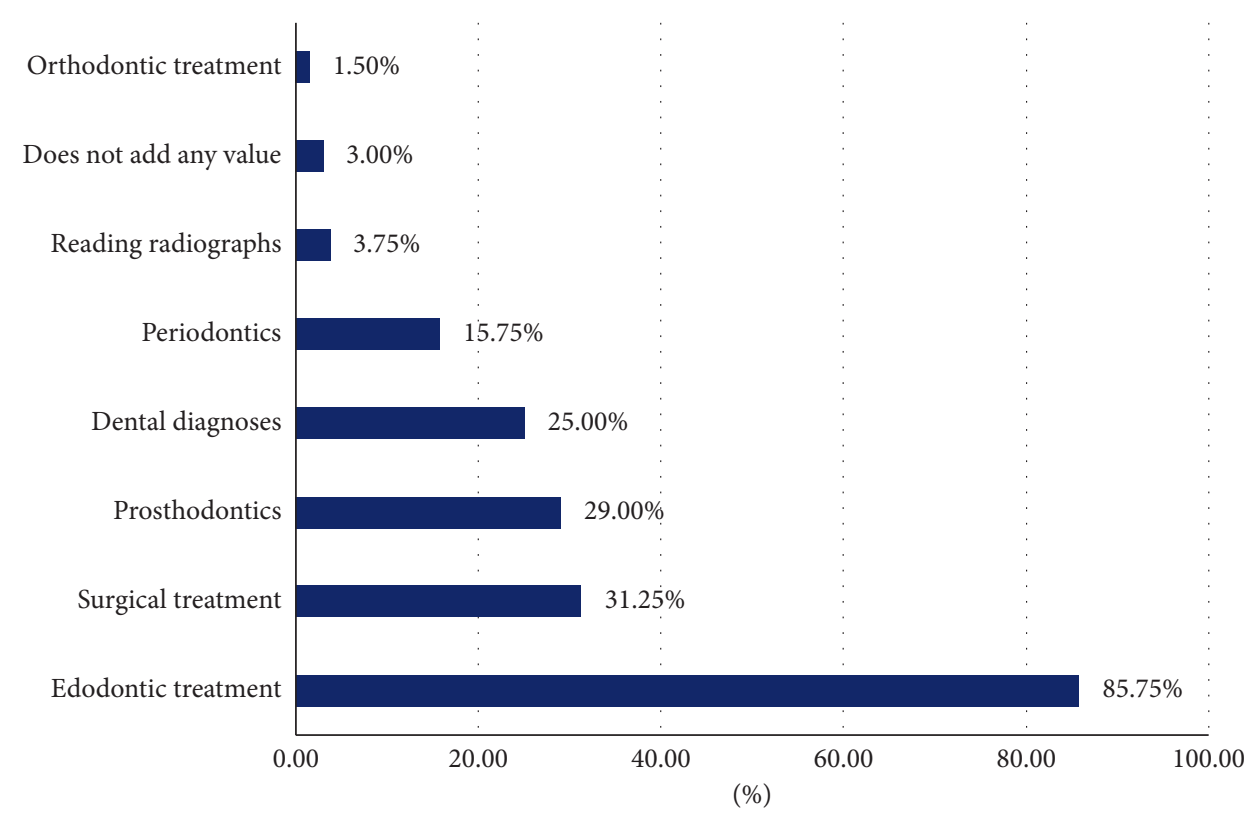

Figure 2: Dental specialties for which dental loupes were believed to be most useful.

TABLE 5: Participant prevalence of musculoskeletal pain related to dentistry.

\begin{tabular}{lcc}
\hline Body part & Previous pain, ache, or discomfort, $N(\%)$ & Pain, ache, or discomfort in the past 7 days, $N(\%)$ \\
\hline Lower back & $254(63.5 \%)$ & $144(36 \%)$ \\
Neck & $261(65.25 \%)$ & $128(32 \%)$ \\
Shoulder & $185(46.25 \%)$ & $75(18.75 \%)$ \\
Elbow & $93(23.25 \%)$ & $31(7.75 \%)$ \\
Wrist & $133(33.25 \%)$ & $38(9.5 \%)$ \\
Upper back & $164(41 \%)$ & $82(20.5 \%)$ \\
Hip & $83(20.75 \%)$ & $44(11 \%)$ \\
Knee & $73(18.25 \%)$ & $49(12.25 \%)$ \\
Feet & $54(13.5 \%)$ & $32(8 \%)$ \\
\hline
\end{tabular}

TABLE 6: The relationship between current and nonusers of dental loupes and a history of recent musculoskeletal trouble in the previous seven days.

\begin{tabular}{|c|c|c|c|c|}
\hline Area & Pain & Currently a nonuser, $N(\%)$ & Current user of dental loupes, $N(\%)$ & $P$ value \\
\hline \multirow{2}{*}{ Lower back } & Yes & $137(39.03)$ & $7(14.29)$ & \multirow{2}{*}{0.001} \\
\hline & No & $214(60.97)$ & $42(85.71)$ & \\
\hline \multirow{2}{*}{ Neck } & Yes & $119(33.9)$ & $9(18.37)$ & \multirow{2}{*}{0.029} \\
\hline & No & $232(66.1)$ & $40(81.63)$ & \\
\hline \multirow{2}{*}{ Shoulder } & Yes & $75(21.37)$ & $0(0)$ & \multirow{2}{*}{$<0.001$} \\
\hline & No & $276(78.63)$ & $49(100)$ & \\
\hline \multirow{2}{*}{ Elbow } & Yes & $31(8.83)$ & $0(0)$ & \multirow{2}{*}{0.022} \\
\hline & No & $320(91.17)$ & $49(100)$ & \\
\hline \multirow{2}{*}{ Wrist } & Yes & $37(10.54)$ & $1(2.04)$ & \multirow{2}{*}{0.067} \\
\hline & No & $314(89.46)$ & $48(97.96)$ & \\
\hline \multirow{2}{*}{ Upper back } & Yes & $80(22.79)$ & $2(4.08)$ & \multirow{2}{*}{0.001} \\
\hline & No & $271(77.21)$ & $47(95.92)$ & \\
\hline \multirow{2}{*}{ Hip } & Yes & $42(11.97)$ & $2(4.08)$ & \multirow{2}{*}{0.141} \\
\hline & No & $309(88.03)$ & $47(95.92)$ & \\
\hline \multirow{2}{*}{ Knee } & Yes & 47 (13.39) & $2(4.08)$ & \multirow{2}{*}{0.065} \\
\hline & No & $304(86.61)$ & 47 (95.92) & \\
\hline \multirow{2}{*}{ Feet } & Yes & $32(9.12)$ & $0(0)$ & \multirow{2}{*}{0.022} \\
\hline & No & $319(90.88)$ & $49(100)$ & \\
\hline
\end{tabular}

information about loupes during their degree studies [25]. It seems that adding dental loupes as a topic in undergraduate curricula might boost dental students and dentists' awareness of this device, given that our study showed a small percentage of participants had not received any formal information about dental loupes before. 
The results of this study are important as it can be a cornerstone to reinforce stakeholders in dental clinic to provide dental loupes as safety measure for dental portioners. This can help them to reduce MSDs and help them to extend their career in healthy condition. Also, it is recommended that dental loupes be included as a topic in undergraduate curricula and that acquisition of dental loupes should be facilitated by subsidizing the costs, especially for dental students.

This study has some strengths, including the data being collected from four different dental colleges, including private ones, in Jeddah, and the use of the Nordic assessment as a validated tool. Among the limitations of the study, however, is that the study used a self-assessment questionnaire with a convenience sample. Also, because data were gathered from only Jeddah, the results do not have extremal validity for Saudi Arabia. It is recommended that a study be conducted to include many dental colleges around Saudi Arabia with a focus on only dental loupes.

\section{Conclusion}

There is a low occurrence of dental loupe use among dental students and dentists in Saudi Arabia. The use of dental loupes was associated with lower levels of MSDs in the lower back, neck, shoulders, elbows, upper back, and feet.

\section{Data Availability}

The data file of this study is available from the corresponding author upon reasonable request.

\section{Conflicts of Interest}

The authors declare that there are no conflicts of interest regarding the publication of this paper.

\section{References}

[1] S. J. Stanbury and J. Elfar, "The use of surgical loupes in microsurgery," The Journal of Hand Surgery, vol. 36, no. 1, pp. 154-156, 2011.

[2] G. B. Carr and C. A. F. Murgel, "The use of the operating microscope in endodontics," Dental Clinics of North America, vol. 54, no. 2, pp. 191-214, 2010.

[3] B. J. Chang, "Ergonomic benefits of surgical telescope systems: selection guidelines," Journal of the California Dental Association, vol. 30, no. 2, pp. 161-169, 2002.

[4] L. M. Rucker and S. Sunell, "Ergonomic risk factors associated with clinical dentistry," Journal of the California Dental Association, vol. 30, no. 2, pp. 139-148, 2020.

[5] J. Mamoun, M. E. Wilkinson, and R. Feinbloom, “Technical aspects and clinical usage of Keplerian and Galilean binocular surgical loupe telescopes used in dentistry or medicine," 2013, http://www.sunbeamdental.com/loupes_dentistry_formatted.pdf.

[6] T. Y. Alhazzazi, N. A. Alzebiani, S. K. Alotaibi et al., "Awareness and attitude toward using dental magnification among dental students and residents at King Abdulaziz University, Faculty of Dentistry," BMC Oral Health, vol. 17, no. 1, p. 21, 2017.

[7] M. P. Maggio, H. Villegas, and M. B. Blatz, "The effect of magnification loupes on the performance of preclinical dental students," Quintessence International, vol. 42, no. 1, pp. 45-55, 2011.

[8] K. Narula, M. Kundabala, N. Shetty, and R. Shenoy, "Evaluation of tooth preparations for class II cavities using magnification loupes among dental interns and final year BDS students in preclinical laboratory," Journal of Conservative Dentistry: JCD, vol. 18, no. 4, p. 284, 2015.

[9] S. A. Farook, R. J. Stokes, A. K. J. Davis, K. Sneddon, and J. Collyer, "Use of dental loupes among dental trainers and trainees in the UK," Journal of Investigative and Clinical Dentistry, vol. 4, no. 2, pp. 120-123, 2013.

[10] M. Meraner and J. B. Nase, "Magnification in dental practice and education: experience and attitudes of a dental school faculty," Journal of Dental Education, vol. 72, no. 6, pp. 698-706, 2008.

[11] B. G. Branson, M. A. Black, and M. Simmer-Beck, "Changes in posture: a case study of a dental hygienist's use of magnification loupes," Work, vol. 35, no. 4, pp. 467-476, 2010.

[12] L. M. Congdon, S. L. Tolle, and M. Darby, "Magnification loupes in US entry-level dental hygiene programs-occupational health and safety," Journal of Dental Hygiene, vol. 86, no. 3, pp. 215-222, 2012.

[13] L. S. Tibbetts and D. Shanelec, "Principles and practice of periodontal microsurgery," The International Journal of Microdentistry, vol. 1, no. 1, pp. 13-24, 2009.

[14] J. S. Mamoun, "A rationale for the use of high-powered magnification or microscopes in general dentistry," General Dentistry, vol. 57, no. 1, pp. 18-26, 2009.

[15] AAE, "AAE special committee to develop a microscope position paper. AAE position statement. Use of microscopes and other magnification techniques," Journal of Endodontics, vol. 38, no. 8, pp. 1153-1155, 2012.

[16] M. I. Malterud, "Magnification: you can't effectively practice minimally invasive biomimetic dentistry without it," General Dentistry, vol. 61, no. 3, pp. 14-17, 2013.

[17] A. Plessas and M. Bernardes Delgado, "The role of ergonomic saddle seats and magnification loupes in the prevention of musculoskeletal disorders. A systematic review," International Journal of Dental Hygiene, vol. 16, no. 4, pp. 430-440, 2018.

[18] P. Perrin, M. Eichenberger, K. Neuhaus, and A. Lussi, "Visual acuity and magnification devices in dentistry," Swiss Dental Journal, vol. 126, no. 3, pp. 126-222, 2016.

[19] M. R. Rayyan, S. C. Hetou, R. F. Al Salem et al., "Work-related musculoskeletal disorders among dental students of different academic levels," Journal of International Oral Health, vol. 8, no. 4, pp. 471-475, 2016.

[20] M. Hayes, D. Cockrell, and D. Smith, "A systematic review of musculoskeletal disorders among dental professionals," International Journal of Dental Hygiene, vol. 7, no. 3, pp. 159$165,2009$.

[21] A. Alghadir, H. Zafar, and Z. A. Iqbal, "Work-related musculoskeletal disorders among dental professionals in Saudi Arabia," Journal of Physical Therapy Science, vol. 27, no. 4, pp. 1107-1112, 2015.

[22] O. Al-Mohrej, N. AlShaalan, W. Al-Bani, E. Masuadi, and H. Almodaimegh, "Prevalence of musculoskeletal pain of the neck, upper extremities and lower back among dental practitioners working in Riyadh, Saudi Arabia: a cross-sectional study,” BMJ Open, vol. 6, no. 6, 2016.

[23] N. A. Almosa and H. Zafar, "Assessment of knowledge about dental ergonomics among dental students of King Saud University, Riyadh, Kingdom of Saudi Arabia," The Journal of 
Contemporary Dental Practice, vol. 20, no. 3, pp. 324-329, 2019.

[24] S. A. Mallikarjun, P. R. Devi, A. R. Naik, and S. Tiwari, "Magnification in dental practice: how useful is it?" Journal of Health Research and Reviews, vol. 2, no. 2, pp. 39-44, 2015.

[25] G. S. Penmetsa, L. P. Mani, G. Praveen, C. D. Dwarakanath, and S. Suresh, "Awareness, attitude, and prevalence of usage of magnification devices among the dental practitioners in the state of Andhra Pradesh-a questionnaire-based study," Journal of Indian Society of Periodontology, vol. 21, no. 2, pp. 398-402, 2017.

[26] I. Kuorinka, B. Jonsson, A. Kilbom et al., "Standardised nordic questionnaires for the analysis of musculoskeletal symptoms," Applied Ergonomics, vol. 18, no. 3, pp. 233-237, 1987.

[27] N. Alaca, E. E. Safran, A. İ. Karamanlargil, and E. Timucin, "Translation and cross-cultural adaptation of the extended version of the nordic musculoskeletal questionnaire into Turkish," Journal Musculoskelet Neuronal Interact, vol. 19, no. 3, pp. 472-481, 2019.

[28] M. Antonopoulou, C. Ekdahl, M. Sgantzos, N. Antonakis, and C. Lionis, "Translation and standardisation into Greek of the standardised general nordic questionnaire for the musculoskeletal symptoms," European Journal of General Practice, vol. 10, no. 1, pp. 33-34, 2004.

[29] E. N. C. de Barros and N. M. C. Alexandre, "Cross-cultural adaptation of the Nordic musculoskeletal questionnaire," International Nursing Review, vol. 50, no. 2, pp. 101-108, 2003.

[30] N. Namnik, H. Negahban, R. Salehi, R. Shafizadeh, and M. S. Tabib, "Validity and reliability of Persian version of the specific nordic questionnaire in Iranian industrial workers," Work, vol. 54, no. 1, pp. 35-41, 2016.

[31] B. A. Albassam, "The public financial system in Saudi Arabia: the need for reform," International Journal on Governmental Financial Management, vol. 19, no. 2, pp. 38-53, 2019.

[32] D. Moshashai, A. M. Leber, and J. D. Savage, "Saudi Arabia plans for its economic future: vision 2030, the national transformation plan and Saudi fiscal reform," British Journal of Middle Eastern Studies, vol. 47, no. 3, pp. 1-21, 2018.

[33] D. E. Meisha, N. S. Alsharqawi, A. A. Samarah, and M. Y. AlGhamdi, "Prevalence of work-related musculoskeletal disorders and ergonomic practice among dentists in Jeddah, Saudi Arabia," Clinical, Cosmetic and Investigational Dentistry, vol. 11, pp. 171-179, 2019.

[34] M. McLaughlin, The effect of educational requirement of magnification loupes on musculoskeletal pain among Ohio registered dental hygienists, Ph.D. thesis, Ohio State University, Columbus, OH, USA, 2019. 